\title{
Surgery and subsequent risk of non-small cell lung cancer recurrence: a meta-analysis of observational studies
}

\author{
Jia Hu, Huikai Miao, Rongzhen Li, Zhesheng Wen \\ Department of Thoracic Oncology, State Key Laboratory of Oncology in South China, Collaborative Innovation Center for Cancer Medicine, Sun \\ Yat-sen University Cancer Center, Guangzhou 510060, China \\ Contributions: (I) Conception and design: J Hu, Z Wen; (II) Administrative support: Z Wen; (III) Provision of study materials or patients: Z Wen; (IV) \\ Collection and assembly of data: J Hu, H Miao, R Li; (V) Data analysis and interpretation: Jia Hu; (VI) Manuscript writing: All authors; (VII) Final \\ approval of manuscript: All authors. \\ Correspondence to: Zhesheng Wen. Department of Thoracic Oncology, State Key Laboratory of Oncology in South China, Collaborative Innovation \\ Center for Cancer Medicine, Sun Yat-sen University Cancer center, 651 Dongfengdong, Guangzhou 510060, China. \\ Email: wenzhsh@sysucc.org.cn.
}

\begin{abstract}
Background: Surgery is the main treatment for stage I, II, and IIIA non-small cell lung cancer (NSCLC). However, the relationship between surgery and NSCLC recurrence is unclear. Thus, we performed a metaanalysis to determine whether surgery is associated with an increased risk of NSCLC recurrence.

Methods: We used the electronic databases in PubMed, Web of Science, EMBASE, Cochrane Library and MEDLINE to carry out a systematic literature search before December 1st, 2017. All studies on the association between surgery and subsequent risk of NSCLC recurrence were included and then analyzed using RevMan 5.3.
\end{abstract}

Results: Eleven studies were included in the meta-analysis involving 3,190 patients. The relationship between surgery and NSCLC recurrence was evaluated by pooled odds ratio (OR) and 95\% confidence interval (CI). The results suggested that surgery does not increase the risk of NSCLC recurrence $(\mathrm{OR}=0.42$, 95\% CI, 0.25-0.72, P=0.001).

Conclusions: Our results showed that surgery decreased the risk of NSCLC recurrence in stage I-IV.

Keywords: Non-small cell lung cancer (NSCLC); recurrence; surgery

Submitted Nov 08, 2019. Accepted for publication Feb 04, 2020.

doi: $10.21037 /$ tcr.2020.02.15

View this article at: http://dx.doi.org/10.21037/tcr.2020.02.15

\section{Introduction}

Lung cancer has become one of the major diseases endangering human health with the highest morbidity and mortality worldwide (1). It has been confirmed that surgical resection is the most effective therapy for stage I, II, and IIIA non-small cell lung cancer (NSCLC) $(2,3)$. However, postoperative recurrence is the most common cause of treatment failure. A growing body of evidence has demonstrated that a considerable proportion of NSCLC patients develop disease recurrence despite curative resection (4), and the post-resection relapse rate remains high, but the causes of NSCLC recurrence are not completely understood. Although the associations between NSCLC recurrence and other factors including TNM classification or tumor markers are clear, the relationship between NSCLC recurrence and surgery is uncertain (5). For example, some studies showed that the NSCLC recurrence rate in the surgical group was higher than that in the control group, while other studies showed that surgery decreased the risk of NSCLC recurrence. As the association between NSCLC recurrence and surgery is unclear, we performed a meta-analysis of the relationship between NSCLC and surgery by reviewing the current literature. 
Table 1 Characteristics of identified studies

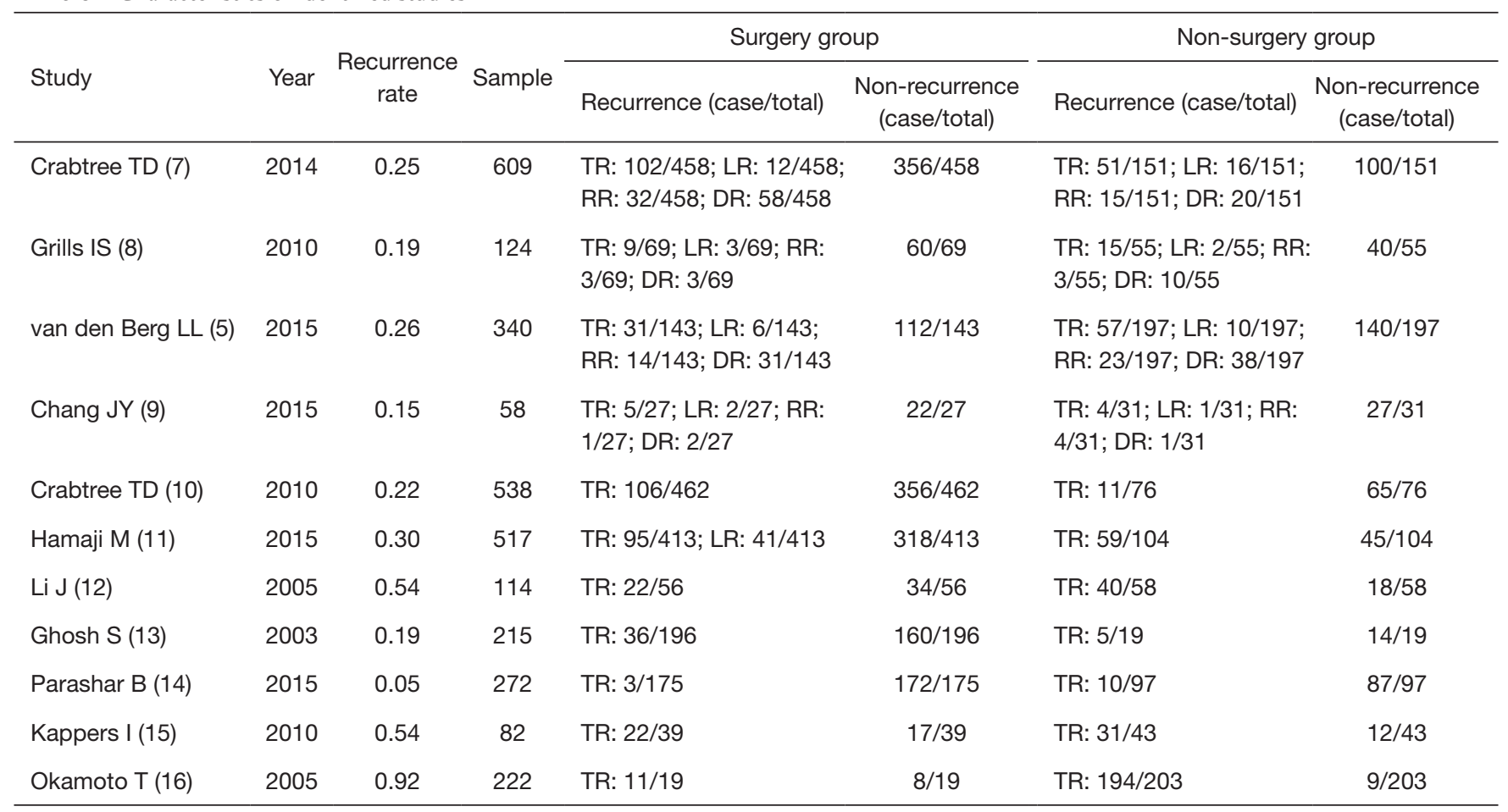

TR, total recurrence; LR, local recurrence; RR, regional recurrence; $D R$, distant recurrence.

\section{Methods}

This systematic review and meta-analysis followed the Cochrane Handbook guidance and the Meta-analysis of Observational Studies in Epidemiology (MOOSE) guidelines (6).

\section{Data sources and the retrieval strategy}

Five electronic databases (PubMed, Web of Science, EMBASE, Cochrane Library and MEDLINE) were searched up to December 1st, 2017. Search terms were "lung neoplasms [MeSH Terms]" and "lobectomy/sublobectomy/ segmentectomy/limited resection" and "recurrence/prognosis/ survival". The titles and abstracts of potential references were scanned to exclude irrelevant articles. The full texts of the remaining relevant articles were carefully read.

\section{Inclusion and exclusion criteria}

We included case-control, cross-sectional and cohort studies on the association between surgery and NSCLC recurrence as well as its two subtypes: local recurrence and tumor metastasis. Exclusion criteria: (I) articles without a control group; (II) the absence of a matched or unmatched unexposed cohort; (III) the incidence of cancer recurrence was not reported. There were no language restrictions related to inclusion in this meta-analysis.

\section{Data extraction}

Two independent investigators carried out the data extraction. The following information was recorded: the last name of the first author, the publication year, country of origin, treatment method, number of patients with NSCLC recurrence in the surgical group and non-surgical group, and adjustments for confounding factors (Tables 1 and 2).

\section{Evaluation of methodological quality}

Two independent investigators used the Newcastle-Ottawa Quality Assessment Scale (NOS) to determine the quality of each study (17). Using a score scale of 0 to 9 , a study was considered to be of high quality if it scored 7 or more stars. The meta-analysis excluded studies of low quality. Table S1 
Table 2 Characteristics of identified studies

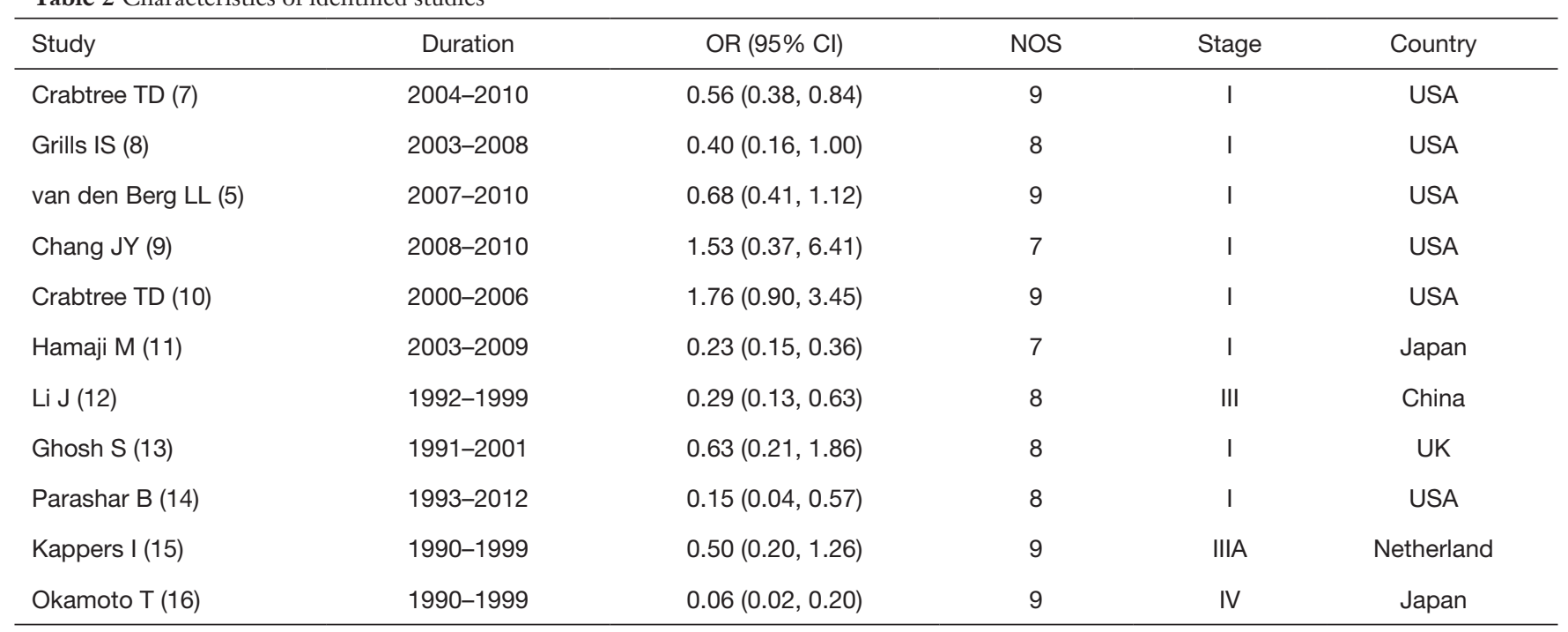

NOS, Newcastle-Ottawa Scale.

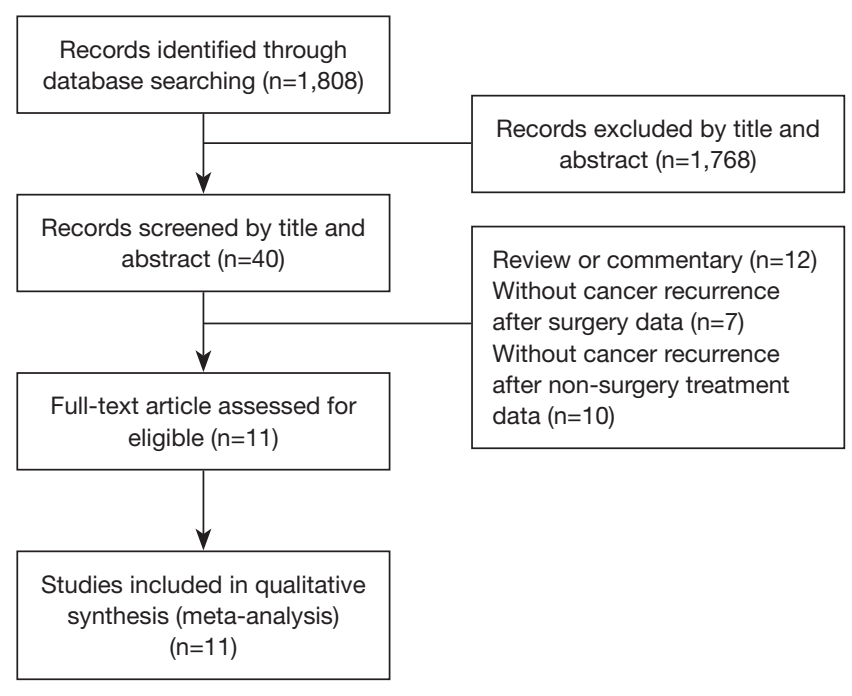

Figure 1 Literature search and screening flow chat.

shows the methodological quality of the included studies.

\section{Data analysis}

Odds ratios (ORs) with $95 \%$ confidence intervals (CIs) were used to estimate effect sizes between NSCLC recurrence and surgery. We obtained ORs and 95\% CIs either directly from each article or calculated them from indirect data, and determined the effective value. In addition, ORs and $95 \%$
CIs were used to evaluate the relationship between NSCLC recurrence and surgery. The heterogeneity of pooled data was tested with Cochran's Q test and Higgins I-squared statistic. $\mathrm{I}^{2}<50 \%$ and $\mathrm{P}>0.1$ were considered to represent no significant heterogeneity and we combined the effective value with the fixed-effects model (18). Otherwise, we adopted the random-effects model. RevMan 5.3 was used for data analysis.

Subgroup analysis was performed to investigate the association between NSCLC and clinical features relating to geographic area and the cancer stage. furthermore, the robustness of the pooled results was examined by sensitivity analysis.

\section{Results}

\section{The selection and characteristics of eligible studies}

Figure 1 shows a flowchart of the selection of eligible studies. The title and abstract of 1,808 studies were scanned and 1,768 of these studies were excluded. based on the title and abstract. We excluded a further twenty-nine studies as they did not meet the inclusion criteria: twelve studies were reviews or commentaries, seven studies did not contain the number of patients who developed cancer recurrence after surgery, and ten studies did not contain cancer recurrence data after non-surgical treatment. Finally, eleven studies were finally included in the current analysis (5,7-16). Basic 


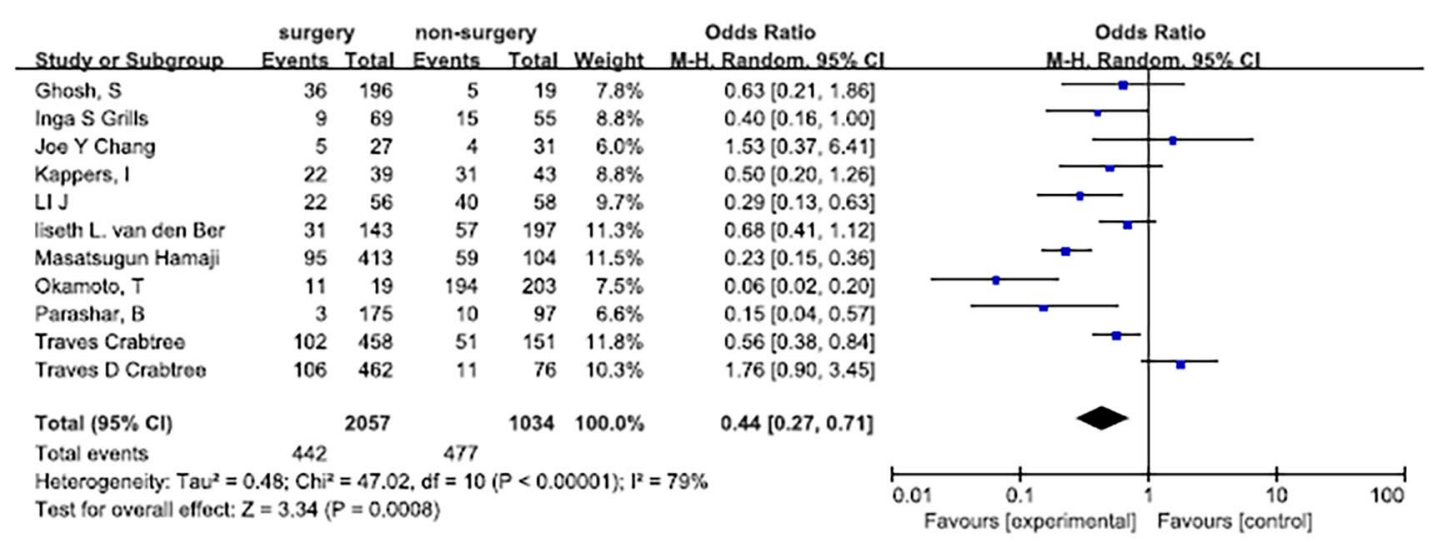

Figure 2 The relationship between surgery and risk of non-small cell lung cancer recurrence forest plot.

\begin{tabular}{|c|c|c|c|c|c|c|c|c|c|c|}
\hline Study or Subgroup & \multicolumn{2}{|c|}{ surgery } & \multicolumn{2}{|c|}{ non-surgery } & \multicolumn{3}{|c|}{ Odds Ratio } & \multicolumn{2}{|c|}{$\begin{array}{c}\text { Odds Ratio } \\
\mathrm{M}-\mathrm{H}, \text { Random. } 95 \% \mathrm{Cl}\end{array}$} & \\
\hline Inga S Grills & 3 & 69 & 2 & 55 & $11.0 \%$ & $1.20[0.19,7.47]$ & & & $=$ & \\
\hline Joe Y Chang & 2 & 27 & 1 & 31 & $6.9 \%$ & $2.40[0.21,28.05]$ & & & & \\
\hline liseth L. van den Ber & 6 & 143 & 10 & 197 & $21.7 \%$ & $0.82[0.29,2.31]$ & & & $=$ & \\
\hline Masatsugun Hamaji & 41 & 413 & 31 & 104 & $33.0 \%$ & $0.26[0.15,0.44]$ & & & & \\
\hline Traves Crabtree & 12 & 458 & 16 & 151 & $27.3 \%$ & $0.23[0.10,0.49]$ & & & & \\
\hline Total $(95 \% \mathrm{Cl})$ & & 1110 & & 538 & $100.0 \%$ & $0.44[0.22,0.90]$ & & & & \\
\hline Total events & 64 & & 60 & & & & & & & \\
\hline Heterogeneity: $\mathrm{Tau}^{2}=$ & .32; $\mathrm{Chi}^{2}$ & $=9.18$ & $\mathrm{df}=4(\mathrm{P}$ & $0.06)$ & $1^{2}=56 \%$ & & 0.01 & 0.1 & 10 & 100 \\
\hline
\end{tabular}

Figure 3 The relationship between surgery and risk of local non-small cell lung cancer recurrence forest plot.

information on the selected studies is listed in Tables 1 and 2.

\section{Main analysis}

Eleven studies consisting of 3,091 patients assessed the association between surgery and NSCLC recurrence (5,7-16). The results showed that surgery was significantly associated with a decreased risk of NSCLC recurrence compared with non-surgical treatment $(\mathrm{OR}=0.44,95 \% \mathrm{CI}, 0.27-0.71)$. There was significant heterogeneity in these studies $\left(\mathrm{I}^{2}=0.79\right.$, $\mathrm{P}<0.00001$ ) (Figure 2).

Five studies including 1,648 participants and 124 cases with local recurrence after surgery were selected for metaanalysis of local recurrence after surgery $(5,7-9,11)$. The results showed that surgery was significantly associated with a decreased risk of local NSCLC recurrence when compared with non-surgical treatment, mainly stereotactic radiation therapy in these studies $(\mathrm{OR}=0.44,95 \% \mathrm{CI}, 0.22$ $0.90, \mathrm{P}=0.02)$. We observed medium heterogeneity in these studies $\left(\mathrm{I}^{2}=0.56, \mathrm{P}=0.06\right)$ (Figure 3).

Four studies including 1,131 participants and 95 cases with regional recurrence after surgery were selected for meta-analysis (5,7-9). The results showed that surgery was not significantly associated with a decreased risk of NSCLC regional recurrence when compared with nonsurgical treatments, mainly stereotactic radiation therapy in these studies $(\mathrm{OR}=0.71,95 \% \mathrm{CI}, 0.46-1.12, \mathrm{P}=0.14)$. No heterogeneity was observed in these studies $\left(\mathrm{I}^{2}=0, \mathrm{P}=0.81\right)$ (Figure 4).

Four studies including 1,131 participants and 163 cases with distant NSCLC recurrence after surgery were selected for meta-analysis (5,7-9). The results demonstrated that surgery was not significantly associated with a decreased risk of distant NSCLC recurrence when compared with nonsurgical treatment, mainly stereotactic radiation therapy in these studies ( $\mathrm{OR}=0.85,95 \% \mathrm{CI}, 0.46-1.59, \mathrm{P}=0.62$ ). Medium heterogeneity was observed in these studies $\left(\mathrm{I}^{2}=0.51, \mathrm{P}=0.11\right)$ (Figure 5).

\section{Subgroup analysis}

Subgroup analyses according to NSCLC stage and source 


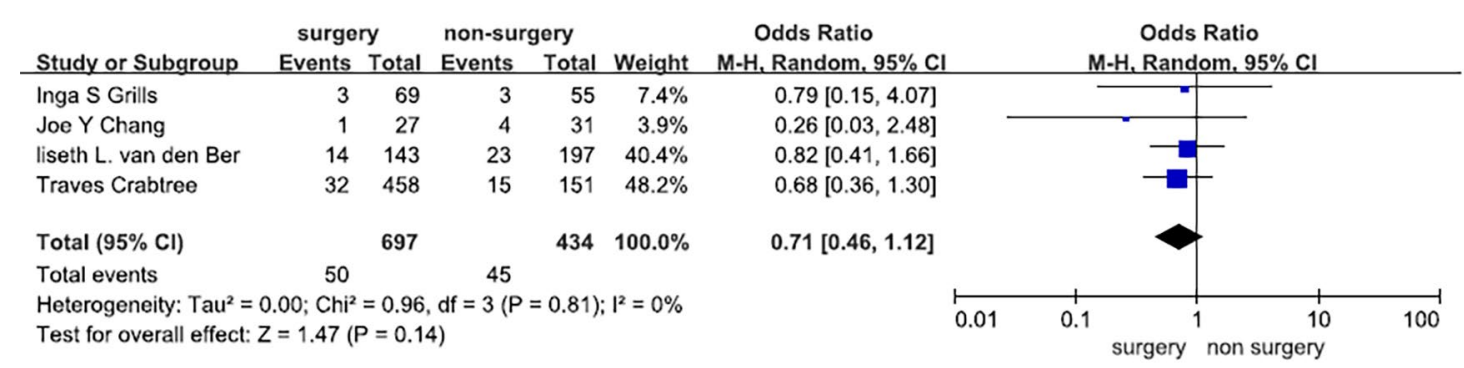

Figure 4 The relationship between surgery and risk of regional non-small cell lung cancer recurrence forest plot.

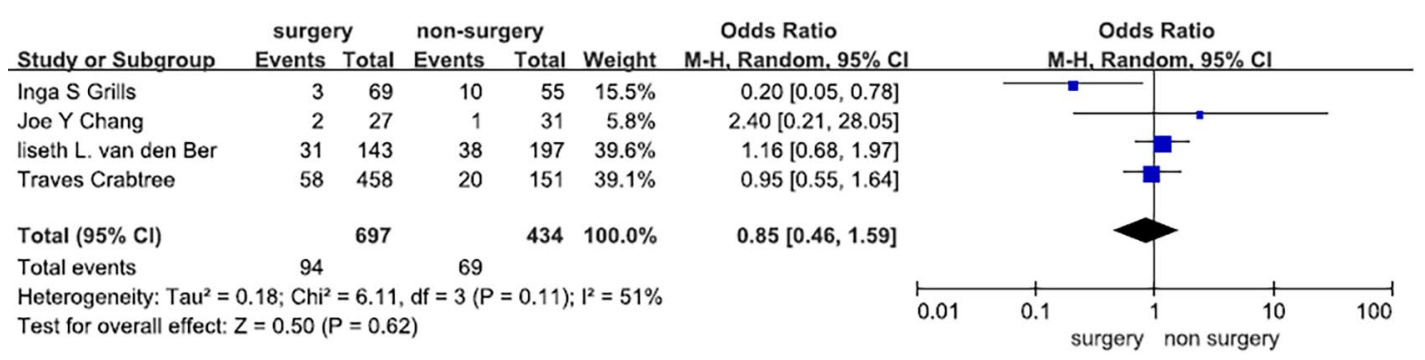

Figure 5 The relationship between surgery and distant non-small cell lung cancer recurrence forest plot.

of data were carried out. In the subgroup analysis according to NSCLC stage, eight studies included patients with stage I-II disease $(5,7-11,13,14)$, and three studies included patients with stage III-IV disease $(12,15,16)$. The result demonstrated that compared with non-surgical treatment, surgery significantly decreased the NSCLC recurrence rate in stage I-II patients ( $\mathrm{OR}=0.55,95 \% \mathrm{CI}, 0.32-0.948)$ $(\mathrm{Z}=2.18, \mathrm{P}=0.03)$.

However, the three studies including 418 patients with stage III-IV NSCLC suggested that surgery was significantly associated with a decreased risk of NSCLC recurrence when compared with non-surgical treatment (OR $=0.22,95 \%$ CI, 0.07-0.66).

In the subgroup analysis of the results according to the source of data, six studies were from the USA $(5,7-10,14)$, while the other five studies were from other countries $(11-13,15,16)$. The results demonstrated that surgery was not significantly associated with a decreased NSCLC recurrence rate in the USA, when compared with nonsurgical treatment $(\mathrm{Z}=1.49, \mathrm{P}=0.14)[\mathrm{OR}=0.66(0.39-1.14)]$.

However, in the non-USA countries, surgery was significantly associated with a decreased NSCLC recurrence rate, when compared with non-surgical treatment $(\mathrm{Z}=4.23$, $\mathrm{P}<0.0001)[\mathrm{OR}=0.27(0.15-0.50)]$. The results of the subgroup analyses are summarized in Table 3.

\section{Analysis of publication bias}

A low probability of publication bias for surgery and NSCLC recurrence was demonstrated by funnel plots (Figure 6).

\section{Sensitivity analysis}

The stability of all pooled results was assessed by sequential omission of each individual analysis in the sensitivity analysis. The pooled OR and heterogeneity were not significantly changed, which demonstrated the robustness of the result.

\section{Discussion}

Tumor recurrence is the most common cause of treatment failure after surgery despite the fact that surgery is widely accepted as a curative treatment for stage I, II, and IIIA NSCLC (19). In the present study, we determined the association between surgery and NSCLC recurrence. Given that surgery is still a widely accepted curative treatment 
Table 3 Subgroup analysis of the relationship between surgery and NSCLC recurrence

\begin{tabular}{|c|c|c|c|c|c|c|c|c|c|c|c|c|}
\hline Variables & \multicolumn{3}{|c|}{ Total recurrence } & \multicolumn{3}{|c|}{ Local recurrence } & \multicolumn{3}{|c|}{ Regional recurrence } & \multicolumn{3}{|c|}{ Distant recurrence } \\
\hline \multicolumn{13}{|l|}{ Countries } \\
\hline USA & 6 & $0.66(0.39,1.14)$ & 0.69 & 4 & $0.63(0.22,1.77)$ & 0.59 & 4 & $0.71(0.46,1.12)$ & 0 & 4 & $0.85(0.46,1.59)$ & 0.51 \\
\hline Non-USA & 5 & $0.27(0.15,0.50)$ & 0.63 & 1 & $0.26(0.15,0.44)$ & - & 0 & - & - & 0 & - & - \\
\hline \multicolumn{13}{|l|}{ Stage } \\
\hline I-II & 8 & $0.55(0.32,0.94)$ & 0.79 & 5 & $0.44(0.22,0.90)$ & 0.56 & 4 & $0.71(0.46,1.12)$ & 0 & 4 & $0.85(0.46,1.59)$ & 0.51 \\
\hline III-IV & 3 & $0.22(0.07,0.66)$ & 0.75 & 0 & - & - & 0 & - & - & 0 & - & - \\
\hline \multicolumn{13}{|l|}{ Sample size } \\
\hline$>300$ & 4 & $0.61(0.29,1.27)$ & 0.89 & 3 & $0.33(0.17,0.63)$ & 0.55 & 2 & $0.74(0.46,1.19)$ & 0 & 2 & $1.05(0.72,1.54)$ & 0 \\
\hline Radiotherapy & 8 & $0.55(0.32,0.94)$ & 0.79 & 5 & $0.44(0.22,0.90)$ & 0.56 & 4 & $0.71(0.46,1.12)$ & 0 & 4 & $0.85(0.46,1.59)$ & 0.51 \\
\hline $\begin{array}{l}\text { Radiotherapy+ } \\
\text { chemotherapy }\end{array}$ & 2 & $0.83(0.03,0.66)$ & 0.80 & 0 & - & - & 0 & - & - & 0 & - & - \\
\hline Chemotherapy & 1 & $0.50(0.20,1.26)$ & - & 0 & - & - & 0 & - & - & 0 & - & - \\
\hline
\end{tabular}

NSCLC, non-small cell lung cancer; OR, odds ratio.

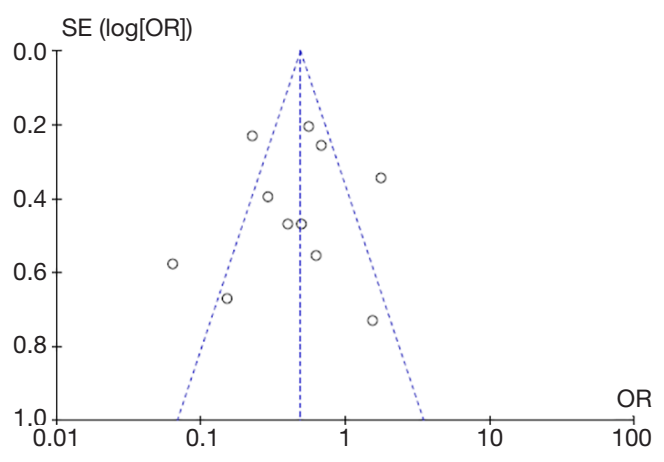

Figure 6 Funnel plots of the association between surgery and risk of non-small cell lung cancer recurrence publication bias. OR, odds ratio.

for stage I, II, and IIIA NSCLC patients $(4,20)$, any potential causal association between surgery and NSCLC recurrence could have a far-reaching impact on public health issues. This meta-analysis demonstrated that surgery was significantly associated with a decreased risk of NSCLC recurrence when compared with non-surgical treatment (OR $=0.44,95 \%$ CI, 0.27-0.71). Moreover, our subgroup analysis further showed that surgery decreased the risk of local NSCLC recurrence, while no significant association was observed between surgery and regional NSCLC recurrence $(\mathrm{OR}=0.71,95 \% \mathrm{CI}, 0.46-1.12, \mathrm{P}=0.14)$ and distant NSCLC recurrence $(\mathrm{OR}=0.85,95 \%$ CI, 0.46-1.59, $\mathrm{P}=0.62$ ).

In previous studies, it was shown that surgical resection resulted in better overall survival and a lower recurrence rate (21). However, other studies demonstrated that in patients who refused surgery, non-surgical treatments such as stereotactic body radiotherapy had the same treatment effects as surgery $(5,7,8)$. In addition, studies have shown that some patients have a rapid and extensive recurrence after surgery $(19,22)$. Although patients with NSCLC receive curative resection, approximately $30 \%$ to $70 \%$ of patients develop postoperative recurrence and die of NSCLC $(4,23)$. The recurrence rate is $>80 \%$ at 2 years after surgery (early recurrence) while the rate of recurrence after 5 years (late recurrence) is 9\% (5). However, our study refuted the findings of previous studies by indicating that surgery can decrease the risk of stage I-IV NSCLC recurrence.

There are several explanations for the association between surgery and NSCLC recurrence. First, it is essential to ensure complete removal of the tumor at the macroscopic and microscopic level. Surgical stress increases disseminated 
tumor cells (DTCs), circulating tumor cells (CTCs) or circulating low-density neutrophils (LDNs) and may increase the risk of cancer recurrence $(24,25)$. Second, treatment of tumor during surgery might lead to the spread of cancer cells $(26,27)$. Third, the number of CD8 $+\mathrm{T}$ cells producing cytokines (IFN $\gamma, \mathrm{TNF}-\alpha$, granzyme B) to tumor-associated antigen is decreased by surgical stress. This effect is caused by impaired $\mathrm{T}$ cell function and reduced cell proliferation. Surgery-induced suppression of tumor-specific CD8+ T cells is the cause of cancer progression after surgery. Postoperative NSCLC metastasis is caused by surgical stress, which injures normal immune function in humans (28). Behrenbruch et al. suggested that the stress response caused by surgery and other perioperative treatments, such as anesthesia and analgesia, can promote the growth of pre-existing micrometastasis or potentially cause tumor spread (29). However, surgery is still the main treatment for stage I, II, and IIIA NSCLC (3). Specifically, surgical resection is considered to be the standard treatment for stage I-II NSCLC and some locally advanced NSCLC $(3,30)$.

Subgroup analysis with respect to the data source demonstrated that in non-USA studies, surgery was significantly associated with a decreased NSCLC recurrence rate and local NSCLC recurrence rate, when compared with non-surgical treatment. In studies from the USA, these differences were insignificant. These results may be influenced by ethnic differences, surgical techniques, research sample size, etc.

Subgroup analysis based on cancer stage indicated that compared with non-surgical treatment, surgery decreased the recurrence rate in stage I-IV NSCLC patients. Despite this, surgeons should also be aware of grasp the indications for NSCLC surgery as some patients fail to improve after surgery and other therapies should be considered.

With regard to non-surgical treatment, subgroup analysis indicated that surgery significantly decreased the cancer recurrence rate compared with radiotherapy and radiotherapy plus chemotherapy. However, compared with chemotherapy, the differences were insignificant. This might be because the sample size in the chemotherapy group was small compared with the surgical group.

However, surgery was not significantly associated with a decreased regional recurrence rate and distant recurrence rate of NSCLC, when compared with non-surgical treatment. Distant metastasis after radical surgery is caused by tumor cells flowing into the pulmonary vein with blood flow (31). The presence of DTCs, CTCs or LDNs may increase the risk of distant NSCLC recurrence.
This meta-analysis was a comprehensive and systematic evaluation of the relationship between surgery and the risk of NSCLC recurrence had some advantages. Firstly, a large number of participants and cases ensured the reliability of the statistical data and conclusions. Secondly, this meta-analysis included case-control and cohort studies to determine the relationship between surgery and NSCLC recurrence. Thirdly, as our results showed that surgery decreased the risk of NSCLC recurrence in stage I-IV patients, surgery is a favorable treatment for curing NSCLC compared with radiotherapy and chemotherapy.

However, there are several limitations related to this article. Firstly, most of the included studies were from the USA and Europe. Therefore, our results might not be applicable to other groups of people. Secondly, the number of NSCLC patients with stage III-IV disease included in the meta-analysis was small; thus, the data may not be sufficient to achieve reliable conclusions in stage IIIIV NSCLC patients treated with surgery. Thirdly, our meta-analysis determined heterogeneity and observed that heterogeneity was partly caused by geographic area, statistical methods, NSCLC stage, sample size, etc. In order to determine the source of heterogeneity in this metaanalysis, subgroup analyses were conducted. The results of the subgroup analyses showed that surgery significantly decreased the risk of NSCLC recurrence not affected by the confounding factors mentioned above. Furthermore, the sensitivity analysis showed that the results were reliable.

In conclusion, this meta-analysis demonstrated that surgery significantly decreased the risk of NSCLC recurrence. Our findings show that early surgical resection is urgently needed to reduce the rate of NSCLC recurrence. Due to the improvements in surgical technique, the overall survival of NSCLC patients has increased (32). More studies are needed to elucidate the underlying causes of the surgical reduction in NSCLC recurrence risk. In addition, surgery can significantly reduce the risk of NSCLC recurrence compared with non-surgical treatment. It would be interesting to examine whether video assisted thoracic surgery or thoracotomy is more favorable in prolonging the survival of NSCLC patients.

\section{Acknowledgments}

We would like to thank all the people helped in data collection and analysis. We are also grateful to all who provided permissions to use and refer to materials. And finally, we would like to thank those who provided helpful 
comments on the paper.

Funding: None.

\section{Footnote}

Conflicts of Interest: All authors have completed the ICMJE uniform disclosure form (available at http://dx.doi. org/10.21037/tcr.2020.02.15). The authors have no conflicts of interest to declare.

Ethical Statement: The authors are responsible for all aspects of the work in guaranteeing that the accuracy of all parts of the work is appropriately investigated and resolved. This study was approved by the Ethics Committee of Sun Yatsen University Cancer Center (approval number: GZR 2018-120).

Open Access Statement: This is an Open Access article distributed in accordance with the Creative Commons Attribution-NonCommercial-NoDerivs 4.0 International License (CC BY-NC-ND 4.0), which permits the noncommercial replication and distribution of the article with the strict proviso that no changes or edits are made and the original work is properly cited (including links to both the formal publication through the relevant DOI and the license). See: https://creativecommons.org/licenses/by-nc-nd/4.0/.

\section{References}

1. Torre LA, Bray F, Siegel RL, et al. Global cancer statistics, 2012. CA Cancer J Clin 2015;65:87-108.

2. Seguin-Givelet A, Lutz J, Brian E, et al. Surgical treatment of early stage non-small cell lung cancer by thoracoscopic segmental resection. Rev Mal Respir 2018;35:521-30.

3. Blandin Knight S, Crosbie PA, Balata H, et al. Progress and prospects of early detection in lung cancer. Open Biol 2017. doi: 10.1098/rsob.170070.

4. Uramoto H, Tanaka F. Recurrence after surgery in patients with NSCLC. Transl Lung Cancer Res 2014;3:242-9.

5. van den Berg LL, Klinkenberg TJ, Groen HJ, et al. Patterns of Recurrence and Survival after Surgery or Stereotactic Radiotherapy for Early Stage NSCLC. J Thorac Oncol 2015;10:826-31.

6. Stroup DF, Berlin JA, Morton SC, et al. Meta-analysis of observational studies in epidemiology: a proposal for reporting. Meta-analysis Of Observational Studies in Epidemiology (MOOSE) group. JAMA 2000;283:2008-12.

7. Crabtree TD, Puri V, Robinson C, et al. Analysis of first recurrence and survival in patients with stage I nonsmall cell lung cancer treated with surgical resection or stereotactic radiation therapy. J Thorac Cardiovasc Surg 2014;147:1183-91; discussion 1191-2.

8. Grills IS, Mangona VS, Welsh R, et al. Outcomes after stereotactic lung radiotherapy or wedge resection for stage I non-small-cell lung cancer. J Clin Oncol 2010;28:928-35.

9. Chang JY, Senan S, Paul MA, et al. Stereotactic ablative radiotherapy versus lobectomy for operable stage I nonsmall-cell lung cancer: a pooled analysis of two randomised trials. Lancet Oncol 2015;16:630-7.

10. Crabtree TD, Denlinger CE, Meyers BF, et al. Stereotactic body radiation therapy versus surgical resection for stage I non-small cell lung cancer. J Thorac Cardiovasc Surg 2010;140:377-86.

11. Hamaji M, Chen F, Matsuo Y, et al. Video-assisted thoracoscopic lobectomy versus stereotactic radiotherapy for stage I lung cancer. Ann Thorac Surg 2015;99:1122-9.

12. Li J, Ma S, Kang S, et al. Evaluation on survival in locally advanced non-small cell lung cancer (NSCLC) for multimodality treatment with or without operation. Zhongguo Fei Ai Za Zhi 2005;8:535-7.

13. Ghosh S, Sujendran V, Alexiou C, et al. Long term results of surgery versus continuous hyperfractionated accelerated radiotherapy (CHART) in patients aged $>70$ years with stage 1 non-small cell lung cancer. Eur J Cardiothorac Surg 2003;24:1002-7.

14. Parashar B, Port J, Arora S, et al. Analysis of stereotactic radiation vs. wedge resection vs. wedge resection plus Cesium-131 brachytherapy in early stage lung cancer. Brachytherapy 2015;14:648-54.

15. Kappers I, van Sandick JW, Burgers SA, et al. Surgery after induction chemotherapy in stage IIIA-N2 non-small cell lung cancer: why pneumonectomy should be avoided. Lung Cancer 2010;68:222-7.

16. Okamoto T, Maruyama R, Shoji F, et al. Long-term survivors in stage IV non-small cell lung cancer. Lung Cancer 2005;47:85-91.

17. Stang A. Critical evaluation of the Newcastle-Ottawa scale for the assessment of the quality of nonrandomized studies in meta-analyses. Eur J Epidemiol 2010;25:603-5.

18. Higgins JP, Thompson SG, Deeks JJ, et al. Measuring inconsistency in meta-analyses. BMJ 2003;327:557-60.

19. Cruz C, Afonso M, Oliveiros B, et al. Recurrence and Risk Factors for Relapse in Patients with Non-Small Cell Lung Cancer Treated by Surgery with Curative Intent. Oncology 2017;92:347-52.

20. Yue D, Gong L, You J, et al. Survival analysis of patients 
with non-small cell lung cancer who underwent surgical resection following 4 lung cancer resection guidelines. BMC Cancer 2014;14:422.

21. Pöttgen C, Eberhardt W, Stamatis G, et al. Definitive radiochemotherapy versus surgery within multimodality treatment in stage III non-small cell lung cancer (NSCLC) - a cumulative meta-analysis of the randomized evidence. Oncotarget 2017;8:41670-8.

22. Mommers EH, Ponten J, Al OA, et al. The general surgeon's perspective of rectus diastasis. A systematic review of treatment options. Surg Endosc 2017;31:4934-49.

23. Dziedzic DA, Rudzinski P, Langfort R, et al. Risk Factors for Local and Distant Recurrence After Surgical Treatment in Patients With Non-Small-Cell Lung Cancer. Clin Lung Cancer 2016;17:e157-e167.

24. Kumagai Y, Ohzawa H, Miyato H, et al. Surgical Stress Increases Circulating Low-Density Neutrophils Which May Promote Tumor Recurrence. J Surg Res 2020;246:52-61.

25. Wang D, Yang Y, Jin L, et al. Prognostic models based on postoperative circulating tumor cells can predict poor tumor recurrence-free survival in patients with stage II-III colorectal cancer. J Cancer 2019;10:4552-63.

26. Lemjabbar-Alaoui H, Hassan OU, Yang YW, et al. Lung cancer: Biology and treatment options. Biochim Biophys

Cite this article as: $\mathrm{Hu} \mathrm{J}$, Miao H, Li R, Wen Z. Surgery and subsequent risk of non-small cell lung cancer recurrence: a meta-analysis of observational studies. Transl Cancer Res 2020;9(3):1960-1968. doi: 10.21037/tcr.2020.02.15
Acta 2015;1856:189-210.

27. Wang S, Hao J, Qian C, et al. Tumor Spread Through Air Spaces Is a Survival Predictor in Non-Small-Cell Lung Cancer. Clin Lung Cancer 2019;20:e584-91.

28. Ananth AA, Tai LH, Lansdell C, et al. Surgical Stress Abrogates Pre-Existing Protective T Cell Mediated Anti-Tumor Immunity Leading to Postoperative Cancer Recurrence. PLoS One 2016;11:e0155947.

29. Behrenbruch C, Shembrey C, Paquet-Fifield S, et al. Surgical stress response and promotion of metastasis in colorectal cancer: a complex and heterogeneous process. Clin Exp Metastasis 2018;35:333-45.

30. Eberhardt WE, De Ruysscher D, Weder W, et al. 2nd ESMO Consensus Conference in Lung Cancer: locally advanced stage III non-small-cell lung cancer. Ann Oncol 2015;26:1573-88.

31. Hashimoto M, Tanaka F, Yoneda K, et al. Positive correlation between postoperative tumor recurrence and changes in circulating tumor cell counts in pulmonary venous blood (pvCTC) during surgical manipulation in non-small cell lung cancer. J Thorac Dis 2018;10:298-306.

32. Myobatake R, Tsubochi H, Nakano T, et al. Techniques and Outcomes of Segmentectomy for Non-small Cell Lung Cancer. Kyobu Geka 2019;72:510-5. 
Supplementary

Table S1 Assessment of methodological studies

\begin{tabular}{|c|c|c|c|c|c|c|c|c|c|}
\hline Study & $\begin{array}{c}\text { Cases } \\
\text { definition }\end{array}$ & $\begin{array}{c}\text { Cases } \\
\text { representativeness }\end{array}$ & $\begin{array}{l}\text { Selection } \\
\text { of controls }\end{array}$ & $\begin{array}{l}\text { Definition } \\
\text { of controls }\end{array}$ & $\begin{array}{l}\text { Comparability } \\
\text { of cases and } \\
\text { controls }\end{array}$ & $\begin{array}{l}\text { Ascertainment } \\
\text { of exposure }\end{array}$ & $\begin{array}{l}\text { Same method } \\
\text { of cases and } \\
\text { controls }\end{array}$ & $\begin{array}{l}\text { Non- } \\
\text { response } \\
\text { rate }\end{array}$ & Score \\
\hline Grills IS (8) & * & * & * & * & * & * & * & * & 8 \\
\hline van den Berg LL (5) & * & * & * & * & ** & * & * & * & 9 \\
\hline Crabtree TD (10) & * & * & * & * & * & ** & * & * & 9 \\
\hline Hamaji M (11) & * & * & * & * & * & * & * & - & 7 \\
\hline Li J (12) & * & * & * & * & * & * & * & * & 8 \\
\hline Ghosh S (13) & * & * & * & * & * & * & * & * & 8 \\
\hline Okamoto T (16) & * & * & * & * & $\star *$ & * & * & * & 9 \\
\hline
\end{tabular}

*, a score of 1. -, a score of $0 .{ }^{* *}$, a score of 2 . 